\title{
4. TEXTURES AND MICROFABRICS IN FINE-GRAINED MUDS AND MUDSTONES FROM SITE 808, NANKAI ACCRETIONARY PRISM ${ }^{1}$
}

\author{
Jan H. Behrmann² and Achim Kopf ${ }^{2}$
}

\begin{abstract}
The microfabric of 11 mudrock specimens from ODP Site 808 (Nankai accretionary prism) was quantitatively analyzed using $\mathrm{X}$-ray texture goniometry and optical petrography. The objectives of the study were to learn about rock strain and to detect a component of bulk lateral shortening in the deformation of the mudstones. Strain evaluation is based on the predictions of March theory, and on distortions of initially homogeneous marker particle distributions (the Fry technique). The main results are as follows. The specimens underwent a strain path of progressive flattening, which is closely related to loss of pore space by vertical loading. A component of bulk lateral shortening is detectable in the top $550 \mathrm{mbsf}$ at Site 808, but compared with the amount of uniaxial vertical shortening, its relative magnitude is probably small. Moreover, it cannot be said with confidence whether this is caused by toe contraction of the accretionary wedge or by gravitationally induced downslope movement of the sediment pile. The mudstones examined were deposited in a marine environment with an oxic bottom water column.

Micropore collapse is an important fabric building mechanism, but below $400 \mathrm{mbsf}$ its effects are at least partly overridden by recrystallization of smectite. We conclude that mud microfabrics are not very precise deformation gauges, but can be used for rough estimations of strain.
\end{abstract}

\section{INTRODUCTION}

Shape and crystallographic preferred orientations of the mineral particles in marine muds and mudstones are due to deformation, which either relates to volume loss during compaction and dewatering (e.g., Oertel and Curtis, 1972; Schiller, 1980), or to tectonically induced shape changes of the rock (e.g., Weber, 1976). Compactioninduced strain relates to volume loss and has a geometry of uniaxial shortening along the vertical direction, whereas tectonically induced strain may or may not have a component of volume loss, and in most cases has a general triaxial geometry.

\section{Lateral Shortening of Accretionary Wedges}

In the frontal part of accretionary prisms, displacement and associated deformation caused by horizontal shortening are localized along comparatively thin movement zones or discrete faults. Fault rocks possess distinct microstructures that can be used to infer mechanisms of deformation. (e.g, Knipe, 1986; Agar et al., 1989, Prior and Behrmann, 1990a, 1990b). Frontal deformation of the Nankai accretionary prism around Site 808 appears to be concentrated in the frontal thrust at $365 \mathrm{~m}$ below seafloor ( $\mathrm{mbsf}$ ) and the basal décollement zone at 945-964 mbsf (Hill, Taira, Firth, et al., this volume). This is in line with the overall picture of the prism as a composition of fault-fold packets (e.g., Aoki et al., 1982). The importance of bulk lateral shortening within the fault-fold packets is less clear, and no attempts have been made to date to quantify the strain in the toe region of accretionary prisms by direct measurements. Using porosity modeling, Brïckmann (1989) has shown that the toe of the Barbados accretionary prism may have undergone bulk horizontal shortening of $2 \%-9 \%$ that is not expressed directly in the form of displacements along thrusts, and we suspect that similar effects could be present in the rocks intersected by the drilling at Site 808 in the toe of the Nankai accretionary prism.

\footnotetext{
${ }^{1}$ Hill, I.A., Taira, A., Firth, J.V., et al., 1993. Proc. ODP, Sci. Results, 131: College Station, TX (Ocean Drilling Program).

2 Institut für Geowissenschaften und Lithosphärenforschung, Universität Giessen, Senckenbergstr. 3, D-6300 Giessen, Federal Republic of Germany.
}

\section{Purpose of the Study}

This paper reports the results of a study of the grain fabric in muds and mudstones taken from the upper $550 \mathrm{~m}$ of core from Holes A, B and $\mathrm{C}$ at Site 808. The intention of the study is first to attempt the quantification of strain in three dimensions by analyzing the crystallographic preferred orientation of smectite with an X-ray texture goniometer. Second, the crystallographic preferred orientation of detrital illites is used to quantify strain in two dimensions. Fabric data from both lines of investigation are used for strain computations on the basis of the model described by March (1932). The third method used here was proposed by Fry (1979), and takes the distortion of an initially homogeneous distribution of marker particles as a measure of strain. Strain magnitude, orientations of principal axes of shortening, and strain type will serve to identify the presence or absence of a component of bulk lateral shortening of the sediment pile as part of the frontal thickening process of accretionary wedges.

\section{Strain Geometries and Orientations}

In the case of deformation related to compaction (Fig. 1A) the state of stress at a point in the sediment is hydrostatic. The resulting strain is uniaxial shortening, and it is due to the collapse of micropores and removal of the pore fluid from the system. The principal shortening axis $(\mathrm{Z})$ is vertical, and elongation (e) in the horizontal plane is zero.

Lateral loading of the sediment pile (Fig. 1B) results in nonhydrostatic stress at a point, whereby the maximum principal compressive stress should be slope-parallel near the mud line, but may be inclined at different angles near faults, depending on their frictional properties and orientations (cf. Davis et al., 1983). The resulting strain in the sediment is triaxial, with the axis of maximum principal shortening (Z) parallel to the orientation of the largest maximum compressive stress. There may or may not be volume loss, which means that the magnitude of elongation parallel to $(\mathrm{X})$ and the volumetric component of strain cannot be readily quantified. Such a component of lateral shortening may be envisaged to result from a process of thrusting and toe contraction at the leading edge of an accretionary wedge, as depicted in Figure 1B. Alternatively this strain pattern is conceivable at the leading edges of submarine landslides floored by a basal décollement much akin to the thrust depicted in Figure 1B. 


\section{A}

volume loss due to compaction and dewatering

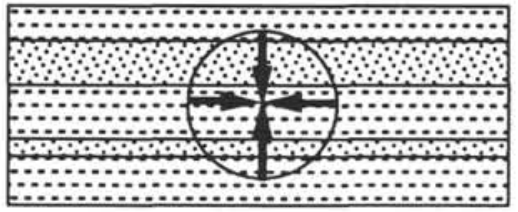

state of stress: hydrostatic tectonically induced shape change

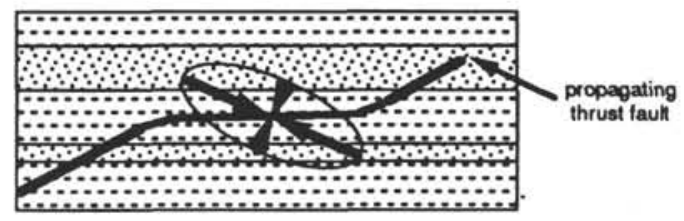

state of stress: non-hydrostatic

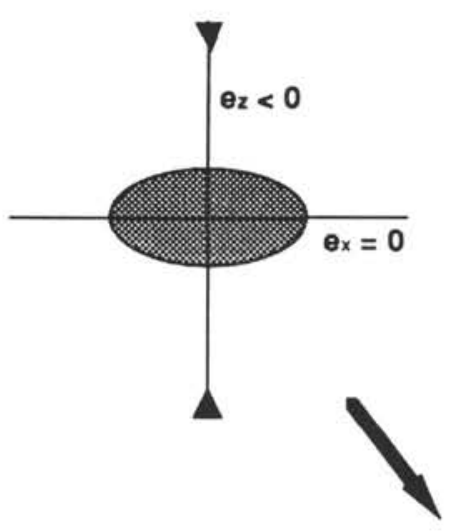

triaxial general strain
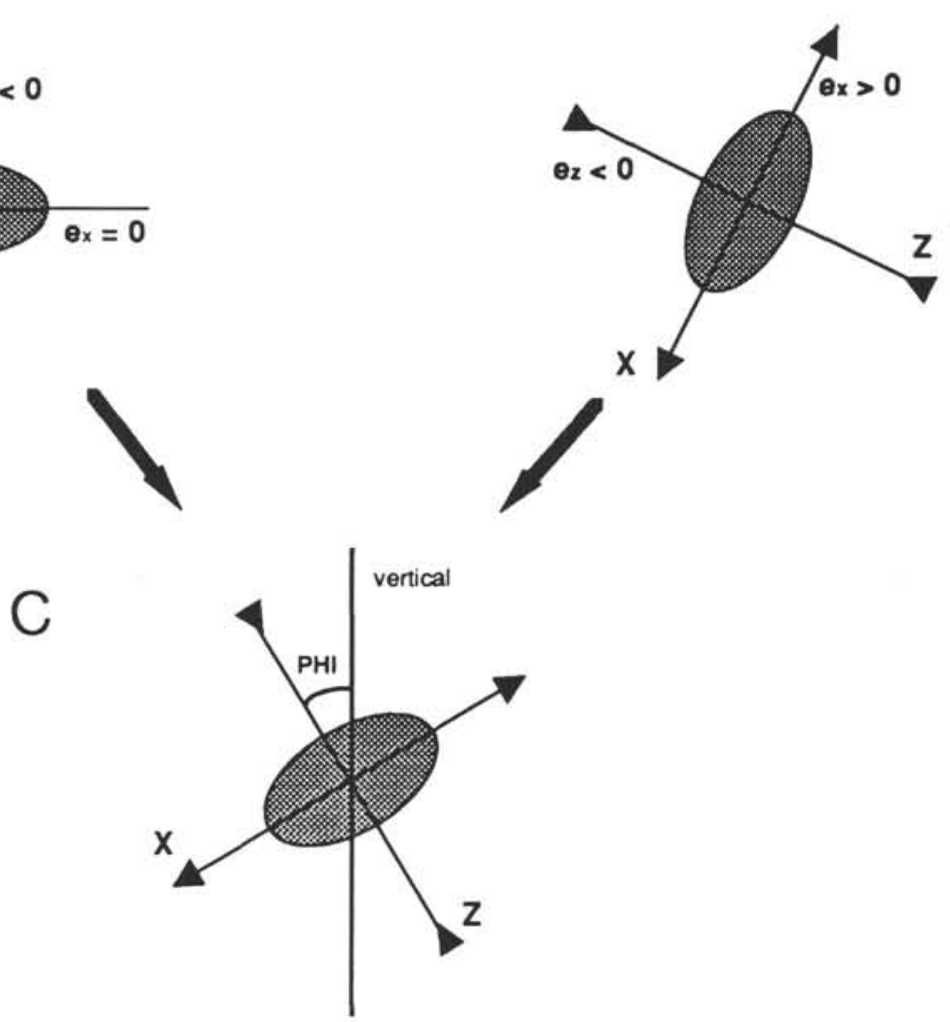

composite strain of sediment

Figure 1. A. Stress and strain geometries at a point in sediment undergoing progressive dewatering and compaction. B. Stress and strain geometries at a point in sediment pile subjected to a horizontal tectonic force. C. Composite strain geometry in sediment after superposition of strains resulting from processes in $\mathbf{A}$ and $\mathbf{B}$.

If composite strains from processes "A" and "B" are considered, the following qualitative predictions can be made about the orientation of principal strain axes and the strain geometry (Fig. 1C).

1. The resulting strain will be generally triaxial. However, if the contribution of component " $\mathrm{B}$ " is small, the composite strain geometry will approximate uniaxial shortening. If three-dimensional strain data are available, this difference can be used to qualify the relative importance of processes "A" and "B."
2. The orientation of $\mathrm{Z}$ will generally deviate from the vertical direction. This is true if the axis of maximum principal extension $(\mathrm{X})$ for process "B" (Fig. 1B) is inclined against the vertical. If $\mathrm{X}$ is horizontal (the special case near the mud line), $\mathrm{X}$ and $\mathrm{Z}$ of composite strain (Fig. 1C) will be horizontal and vertical.

3. In a two-dimensional section containing the vertical direction the axial ratio $\left(R_{f}=X / Z\right)$ of the composite finite strain ellipse (Fig. 1C) is less than it would be for a given amount of vertical shortening $\left(\mathrm{e}_{2}\right.$ in Fig. 1A) due to porosity reduction alone. 


\section{SAMPLE MATERIAL}

\section{Geological Setting}

Drilling at Site 808 intersected $1289.9 \mathrm{~m}$ of sediments at the toe of the Nankai accretionary wedge (Fig. 2) and an additional $38.1 \mathrm{~m}$ of acidic volcaniclastic deposits and basaltic oceanic basement (see Taira, Hill, Firth, et al., 1991). The specimens investigated in this study are muds and mudstones from the depth interval between 23.39 mbsf and 533.40 mbsf (Table 1). Between 0 and $250 \mathrm{mbsf}$ the sediments show little signs of mesoscopic deformation (Fig. 2). Beneath this depth, mesoscopic deformation of the rock column is expressed by shear bands and discrete brittle faults. The specimens themselves show no signs of mesoscopic deformation in the wet state. A weak fissility in the samples from Hole $\mathrm{C}$ becomes obvious after freeze-drying and impregnation with epoxy resin (see below). Mudline porosities are about $65 \%$. Downhole porosities decrease in an exponential fashion to a mean value of about $45 \%$ at $550 \mathrm{mbsf}$ (Taira, Hill, Firth, et al., 1991).

ODP LEG 131 - SITE 808

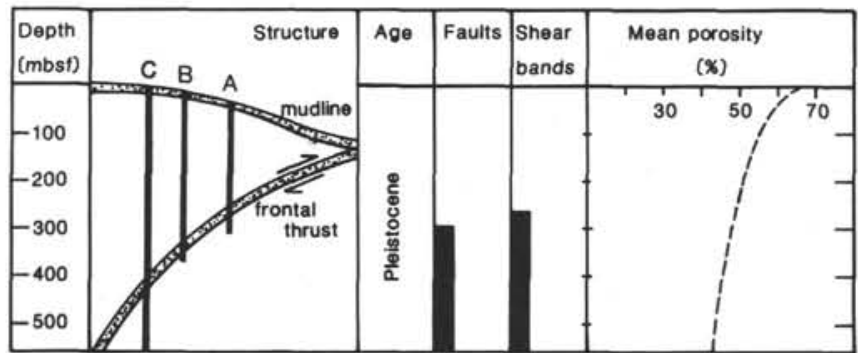

Figure 2. Simplified log of structural and petrophysical features in the upper $550 \mathrm{mbsf}$ of Site 808. See text.

Table 1. Sample codes and depths below seafloor.

\begin{tabular}{lc}
\hline \multicolumn{1}{c}{ Sample code } & $\begin{array}{c}\text { Sample depth } \\
\text { (mbsf) }\end{array}$ \\
\hline JHB 131-808A-3H-6, 19-21 cm & 23.39 \\
JHB 131-808A-9H-1, 139-141 & 69.69 \\
JHB 131-808B-2X-1, 15-17 & 120.75 \\
JHB 131-808B-17X-3, 70-72 & 267.10 \\
JHB 131-808C-4R-1, 123-125 & 328.43 \\
JHB 131-808C-12R-3, 32-34 & 407.92 \\
JHB 131-808C-20R-5, 78-80 & 488.48 \\
JHB 131-808C-22R-5, 46-48 & 507.46 \\
JHB 131-808C-25R-3, 8-10 & 533.08 \\
JHB 131-808C-25R-3, 24-26 & 533.24 \\
JHB 131-808C-25R-3, 40-42 & 533.40 \\
\hline
\end{tabular}

\section{Petrography}

Clay minerals present and detectable by X-ray diffraction in the specimens are smectite, chlorite, illite, and kaolinite. Most of the clay forms a very fine-grained $(<0.005 \mathrm{~mm})$ matrix barely resolvable in the optical microscope. Detrital illite platelets are up to $0.05 \mathrm{~mm}$ long. The non-clay components $(5 \%-30 \%)$ of the samples are angular to rounded bioclastic calcite, clasts of plagioclase and quartz, rare framboidal pyrite, and occasional heavy minerals. Component sizes up to $0.1-\mathrm{mm}$ sections parallel to the core axis show a variably strong preferred shape alignment of detrital illite and elongate calcite and plagioclase clasts. In sections normal to the core axis there is no visible preferred alignment of these components.

\section{Specimen Preparation}

We received the specimens in wet condition immediately after the termination of Leg 131. The course of sample preparation is depicted in the flow chart in Figure 3. The wet samples were freeze-dried at a minimal temperature of $-30^{\circ} \mathrm{C}$ for a period of 3 days. Immediately afterward they were impregnated with epoxy resin (resin: Glycidether 162/Deutsche Shell Chemie; Hardener: Laromin C620/BASF). After they hardened, the samples were cut dry parallel to the core axis. The cut surfaces were again impregnated with epoxy resin, and then ground carefully with 400 and 800 grit silicium carbide until all saw marks were removed. To avoid artifacts on the specimen surface, ethanol was chosen as a grinding fluid (see Prior and Behrmann, 1990a). The ground surface of one of the subsamples was then mounted to a thin-section slide using beeswax supplied by a local beekeeper, and thick sections $(0.1-0.3 \mathrm{~mm})$ for X-ray texture measurements in transmission mode were produced. The thick sections were removed from the slides by brief heating to $60^{\circ} \mathrm{C}$, cleansed using xylol, and mounted to scotch tape. The ground surface of the remaining sample was used for X-ray texture measurements in reflection mode. After texture measurements, ultra-thin sections were prepared from the reflection subsamples for petrographic inspection and fabric analysis in the optical microscope. Additionally, ultra-thin sections were also prepared normal to the core axis to allow visual checks for microfabric anisotropy in the optical microscope.

working scheme of sample preparation

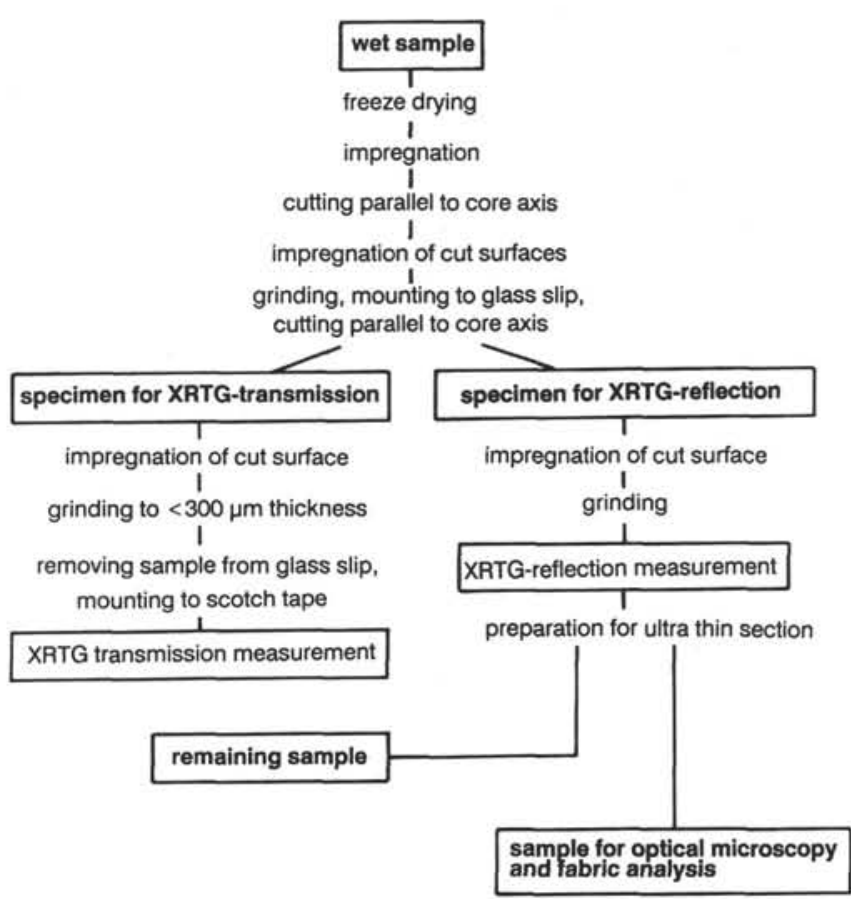

Figure 3. Working scheme of sample preparation for X-ray texture goniometry (XRTG) and optical microscopy and fabric analysis.

\section{ANALYTICAL METHODS \\ X-ray Texture Analysis}

X-ray texture analyses (e.g., Wenk, 1985) were carried out with a computer controlled Siemens D500TX texture goniometer, operating in combined reflection and transmission modes (Siddans, 1976). In 
this way, complete pole figures can be determined. Measurements were made using $\mathrm{Cu} \mathrm{K} \alpha$ radiation at $40 \mathrm{kV}$ and $30 \mathrm{~mA}$. To restrict scattered radiation, which presents a severe problem at the low $(2 \theta=$ $\left.5.7^{\circ}\right)$ diffracting angles used, aperture diaphragms of $0.1^{\circ}$ width were used. Detector apertures were not used. Measurements were carried out in step-scan mode with step widths of $10^{\circ}$ for every twist and tilt increment of the Eulerian cradle. Maximum tilt for reflection measurements was $60^{\circ}$. Corrections of the transmission measurements were applied for specimen thickness and absorption. Reflection measurements were corrected for defocusing and effects of specimen geometry (von Gehlen, 1960). The correction function was derived empirically from the defocusing behavior of the peak and background radiation (Behrmann, 1991). The $2 \theta$ angles for measurement of the background radiation were $4^{\circ}$ and $14^{\circ}$, respectively. Reproducibility of the texture determinations was checked by carrying out measurements at different stages of sample preparation and different specimen orientations (see paragraph below on data). The good reproducibility indicates that the corrections applied were successful in removing artifacts of the measurements, and that specimen preparation did not significantly alter the textures. Trials revealed that textures could be analyzed most successfully using the $(001)$ reflection of smectite at $2 \theta=5.7^{\circ}$.

\section{Fabric Quantification Using Optical Microscopy}

The two-dimensional fabric in sections parallel to the core axis was quantified in two ways. Firstly the degree of preferred orientation of detrital illite flakes was determined by measuring the orientations of the traces of (001) relative to the core axis (Fig. 4). This is expressed in the angle $\alpha$. Video equipment fitted to an optical microscope was used to determine $\alpha$. Photomicrographs should not be used for this type of evaluation, as part of the population of illites will be in extinction when crossed polarizers are used. Histograms of the frequency of illite orientation vs. $\alpha$ were plotted for each specimen. According to the predictions of the March (1932) model, a Gaussian frequency distribution can be interpreted as the result of homogeneous deformation of the ultra-fine-grained clay matrix, and its shape is used for strain calculations (see below). The second way of two-dimensional fabric analysis uses the simple graphical method of Fry (1979, see also the description of Ramsay and Huber, 1983, p. 111, ff) and the PODI-technique (Unzog, 1990) to determine the distortion of an initially statistically homogeneous distribution of marker particles in the sediment. These marker particles may be the centers of detrital illite grains, quartz or plagioclase clasts, calcite bioclasts, or opaques (Fig. 4). A computer program package evaluates the directional differences of marker particle spacings for strain. The axial ratio $\left(R_{f}\right)$ of the strain ellipse is read visually from a Fry-plot (Fig. 5A), and from the amplitude of a sine function derived from the population of marker particle spacings by a least-squares fit (Fig. 5B).

\section{DATA}

\section{X-ray Texture Analysis}

Fourteen pole figures were determined from the specimens listed in Table 1. Figure 6 shows lower hemisphere, equal-area pole projections of smectite (001). The 10 pole figures in the upper three rows are complete, and were measured in combined transmission and reflection modes after specimen preparation. The core axis lies in the plane of projection, and its position is marked by the closed triangles. C-20R-5 (lower left in Fig. 6) is another example for a complete pole figure, but the core axis is oriented normal to the plane of projection. The remaining three pole figures in the lower row of Figure 6 are incomplete, and were exclusively measured in reflection mode. These three subsamples were analyzed wet, immediately after opening the airtight bags after transport from the ship. Sections normal to the core axis were chipped off the samples, and placed in the texture goniometer for measurement. This subsampling was tried on all specimens,

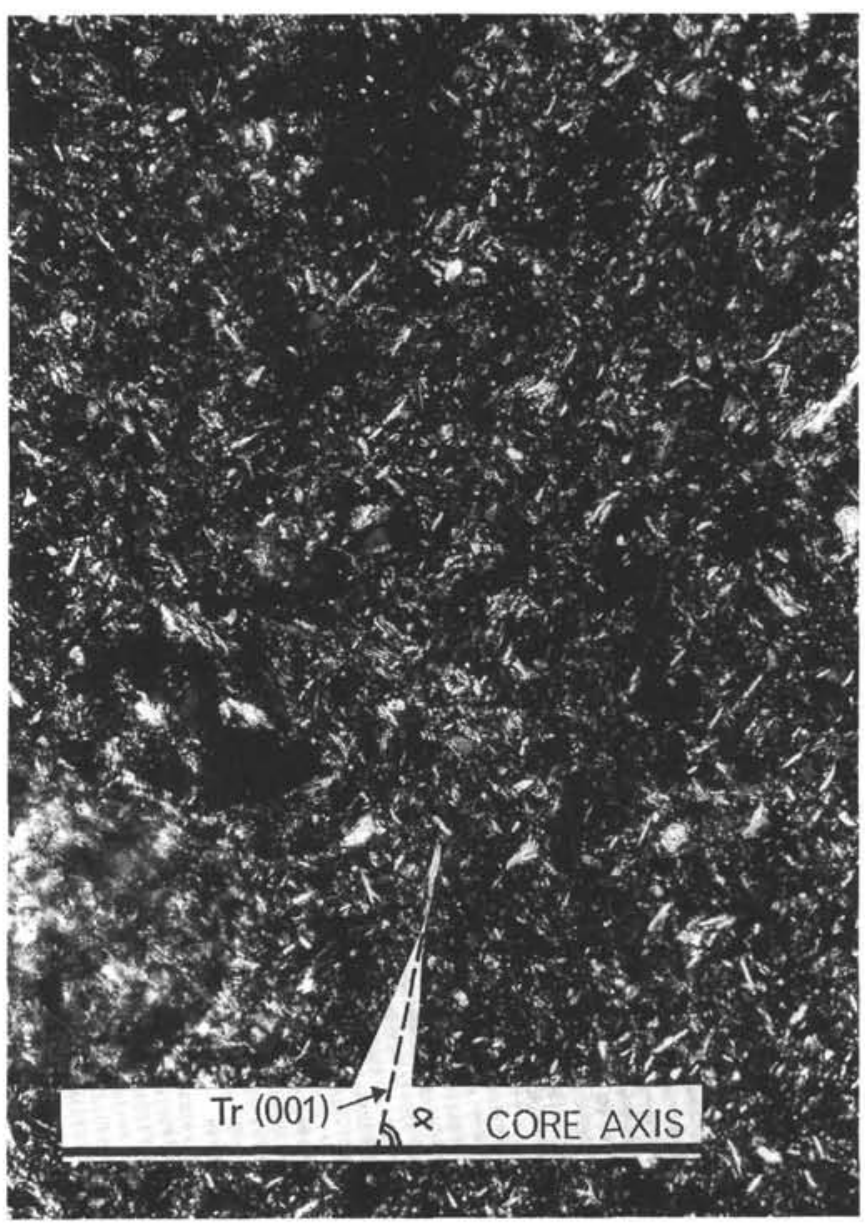

Figure 4. Typical microstructure of mudstone from Site 808, transmitted light, crossed polarizers. Long side of micrograph is $0.39 \mathrm{~mm}$. Specimen is from Section 131-808C-66R-3. $\operatorname{Tr}(001)$ : Basal trace of detrital illite; $\alpha$ : angle between core axis and $\operatorname{Tr}(001)$.

but only the three subsamples represented in Figure 6 had an undamaged surface smooth and planar enough to warrant measurements with low risk of including artifacts. Analyzing the wet samples and comparison with the results from the dry measurements provides an important check for the accuracy of corrections applied to the complete pole figure determinations. Furthermore, changes introduced to the grain fabrics by the drying and impregnation procedure cannot remain undetected.

We shall now discuss the pole figures in Figure 6 from shallow to deep in the Holes A-C at Site 808 . The prefix "131-808" will be omitted. A-3H-6 and A-9H-1 do not show strong preferred orientations, and there is no axially symmetric distribution of the poles around a single-point maximum, as should be the case if these preferred orientations were the result of significant deformation. In fact, the double-maximum preferred orientation patterns seen in A-3H-6 and A-9H-1 may be remnants of the "honeycomb" texture (Terzaghi, 1925) formed during flocculation of clay particles in seawater (e.g., von Engelhardt and Gaida, 1963). Axially symmetric distributions around a point maximum are evident in all pole figures beyond 120 mbsf (see Table 1) i.e., from B-2X-1 to C-25R-3, 40-42 $\mathrm{cm}$. Slight deviations from axial symmetry of the textures are evident in C-4R-1 (dry and wet measurements), C-12R-3 (wet measurement) and C-25R-3, 24-26 cm (dry and wet measurements). A remarkable feature is the consistent inclination of the point maximum with respect to the core axis at angles (PHI in Fig. 6) between $24^{\circ}$ and $48^{\circ}$. The peak intensity recorded in multiples of uniform distribution increases 
a

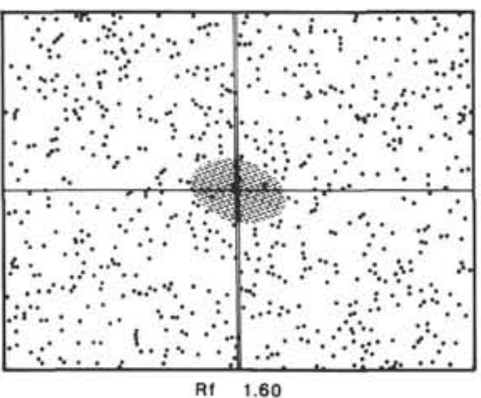

FRY b

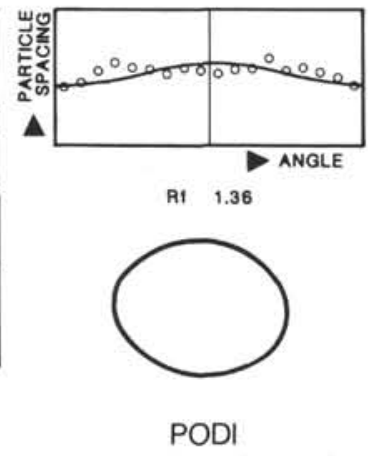

Figure 5. Results of Fry and PODI strain determinations on specimen 131808B-17X-3, 70-73 cm. Marker particles are opaques in thin section. A. Visual estimation using the Fry technique. Vertical double line is orientation of the core axis. Shaded area in the center of the diagram is the visually estimated shape of the strain ellipse. B. Result of the PODI strain calculation.

gradually with depth. Comparing the values of maximum intensity between the wet and dry measurements, we find that C-4R-1 and C-25R-3, 24-26 cm, match perfectly, and that in C-12R-3 there is a difference of about $15 \%$. Correlation of PHI is perfect in C-12R-3, but less impressive in C-4R-1 and C-25R-3, 24-26 cm. Some of the differences seen may be caused by the different grain sample recorded, and in summary we think that reproducibility between wet and dry measurements is good enough to be sure that the dry pole figure determinations represent recordings of the in situ smectite textures.

\section{Orientation Analysis of Detrital Illites}

The data base for strain calculations from preferred orientation of detrital illites is presented in Figure 7. In the diagrams the frequency of occurrence of the poles to basal (001) planes of illite is recorded relative to a reference line that is perpendicular to the core axis. The deviation from the reference line is expressed by the angle $\alpha$. Frequency refers to intervals of $10^{\circ}$ for $\alpha$. In the following, the diagrams in Figure 7 are discussed from shallow to deep in the Holes A-C at Site 808 . A-3H-6 and A-9H-1 do not show strong preferred orientations, and in A-3H-6 there is no obvious Gaussian frequency distribution. The highest maximum is oriented subparallel to the core axis. Downhole from A-9H-1 approximate Gaussian frequency distributions with variable maxima are developed. The maximum in A-9H-1 is subparallel to the core axis, but all other samples show a characteristic mismatch of $30^{\circ}-40^{\circ}$ relative to the core axis.

\section{Marker Particle Fabrics}

All samples were analyzed for the distortion of marker particle populations, but only six of them yielded results of satisfactory quality either using the Fry or PODI technique, or both. The results are listed in Table 2, and B-17X-3 is presented as an example in Figure 5. The fact that the area in the center of the Fry plot is not entirely devoid of points, and the imperfect fit of the data to the sine function in the PODI diagram, indicate that the initial marker particle distribution was not of perfect quality for analysis. Doubts are appropriate as to their general precision. Marker types are either opaques or illite. The values for $R_{f}$ (Table 2) do not show a distinct downhole increase.

\section{STRAIN EVALUATION}

Strain calculations on the basis of the March (1932) theory are possible from the smectite textures and preferred orientation patterns of detrital illite. The two equations found in Figure 8 (lower left) are based on the derivations published by Lipshie (1984) or Oertel (1985), which to our knowledge are the most commonly used formulations of March theory. $I_{\max }$ is the maximum recorded intensity of the diffracted beam as multiples of uniform distribution, $f_{\max }$ and $f_{\text {uniform }}$ are the maximum and uniform frequencies in the histograms in Figure 7 , and $e_{z}$ is the elongation parallel to the principal shortening axis (Z).

The application of March (1932) theory to the natural deformation of clay-rich rocks can be questioned, because it requires the particles to rotate freely without mutual interaction. With the abundance of grain-grain contacts in the specimens studied, unconstrained rotation as a function of strain is clearly not a realistic model, and March (1932) theory cannot be trusted to completely describe the fabric building process in clay and claystone. On the other hand Wood and Oertel (1980) have shown in their Figure 9 a very close correlation between strains measured from the ellipticities of reduction spots and those calculated from phyllosilicate textures in slates from the Cambrian of North Wales. We shall here adopt the position that there is some empirical support for the use of the March (1932) model in the calculation of strain, but that the application of the theory to the problem cannot be fully justified.

Strains from the results of smectite texture analysis are listed in Table 3. Shortening parallel to Z ranges from $21 \%$ to $37 \%$, and there is a general downhole increase in $\mathrm{e}_{z}$. Strains from illite preferred orientations are found in Table 4. In these analyses, shortening parallel to $\mathrm{Z}$ varies between $31 \%$ and $47 \%$. The depth-strain relationship is not straightforward, but it can be stated that samples from the Hole $808 \mathrm{C}$ hole show higher shortening than those from Holes $808 \mathrm{~A}$ and $808 \mathrm{~B}$. Elongations parallel to $\mathrm{Z}$ from the axial ratios $\left(\mathrm{R}_{\mathrm{f}}\right)$ of Fry and PODI strain ellipses can be calculated using the equation found in Figure 8 (lower right) under the assumption that fabrics are axially symmetrical. Values for $\mathrm{e}_{\mathrm{z}}$ from Fry and PODI analyses are listed in Table 2 . They record shortening parallel to $\mathrm{Z}$ between $28 \%$ and $41 \%$.

A comparison of the strain data obtained by the three methods of analysis reveals some interesting quantitative aspects. If compared with the strains recorded by illite orientations and marker particle fabrics, the smectite textures almost consistently memorize lower strains (Figs. 9A, 9B) and linear regression on the data yields graphs that intersect the $\mathrm{Y}$-axis at values for shortening between $6 \%$ and $13 \%$. The data cluster on the diagonal (dashed line) in Figure 9C shows a general agreement of data from illite orientations and Fry-PODI fabrics, although the match in individual specimens is not too good. There are two possible explanations for the differences in the strain record between smectite and illite or Fry-PODI. First, freeze-drying may have affected the mineral-scale texture of smectite by bending of the (001) planes during dehydration (the "corn flake effect"). However, the degree of preferred orientation of smectite in those specimens that were measured wet (Fig. 6 and Table 3) is equally low or even lower when compared to the measurements on the same samples made under dry conditions. This corroborates observations of Prior and Behrmann (1990), who could not find significant preparation damage in their electron microscope study on smectite polycrystals in cores from the Barbados area drilled during Leg 110, which were freeze-dried in a comparable fashion. The second possibility is that selective low-temperature recrystallization lowers the degree of crystallographic preferred orientation of the smectite. Here we are unable to prove this idea independently. However, formation temperatures encountered at Site 808 (Taira, Hill, Firth, et al., 1991) are well outside the range typical for diagenetic overprinting of illite, so that similar processes for the illite are unlikely.

Variation of strains with depth in the borehole is depicted in Figure 10. Increase of ez with depth is not very pronounced, but according to the exponential functions derived for the consolidation of fine-grained sediments in the literature (e.g., Athy, 1930; Sclater and Christie, 1980; Hamilton, 1976; Brückmann, 1989), much of the porosity loss occurs in the top $100 \mathrm{~m}$ of the sediment column. At this point it is interesting to compare the strains measured from fabrics with those to be derived 


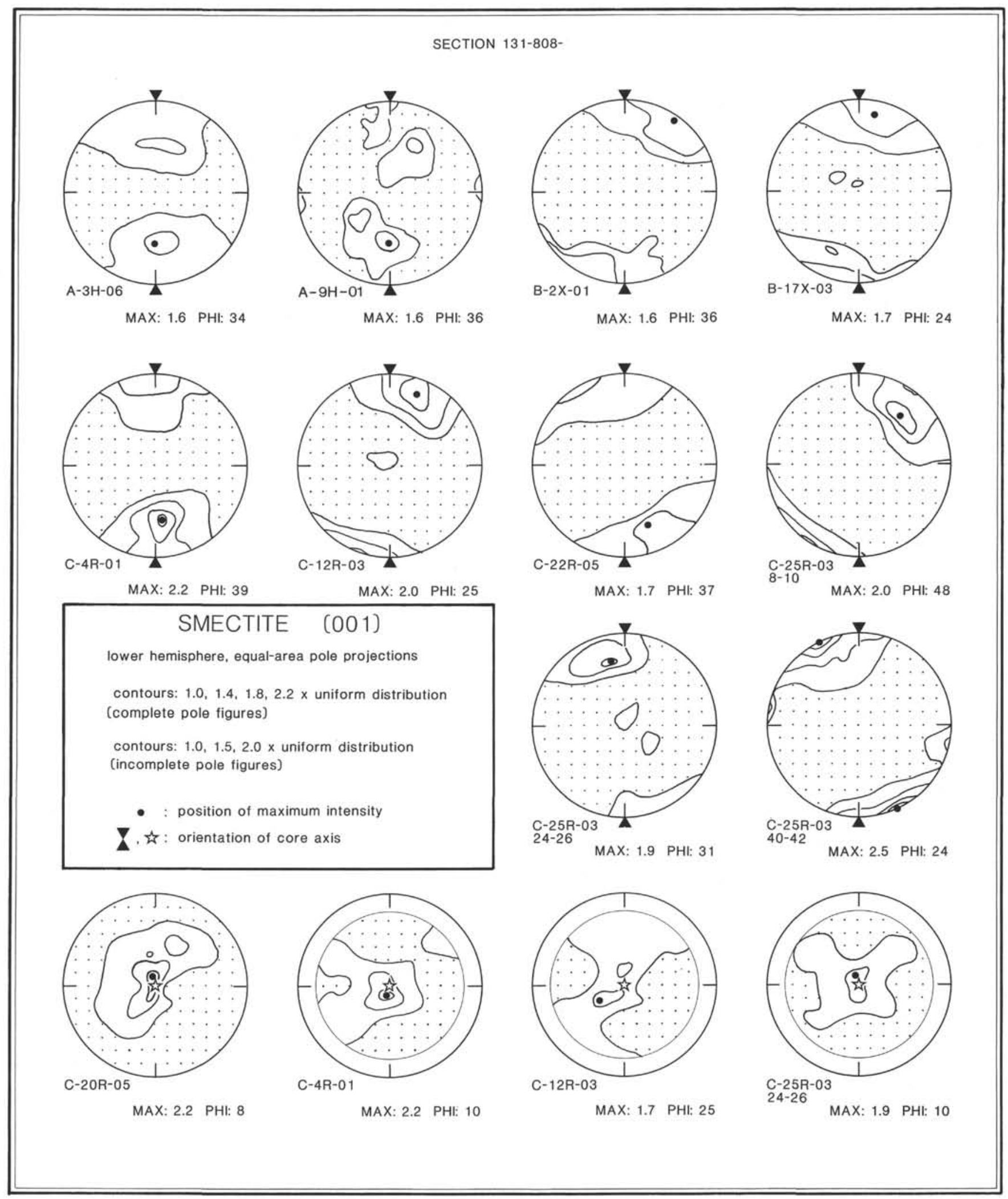

Figure 6. Plots of lower hemisphere, equal-area projections of poles to (001) of smectite in specimens from Site 808. Pole figures in the upper three rows represent dry measurements in plane parallel to the core axis. Lower left pole figure presents dry measurement in plane normal to the core axis. Three incomplete pole figures at lower right represent measurements made on wet, unprepared samples in plane normal to the core axis. 
SECTION 131-808-
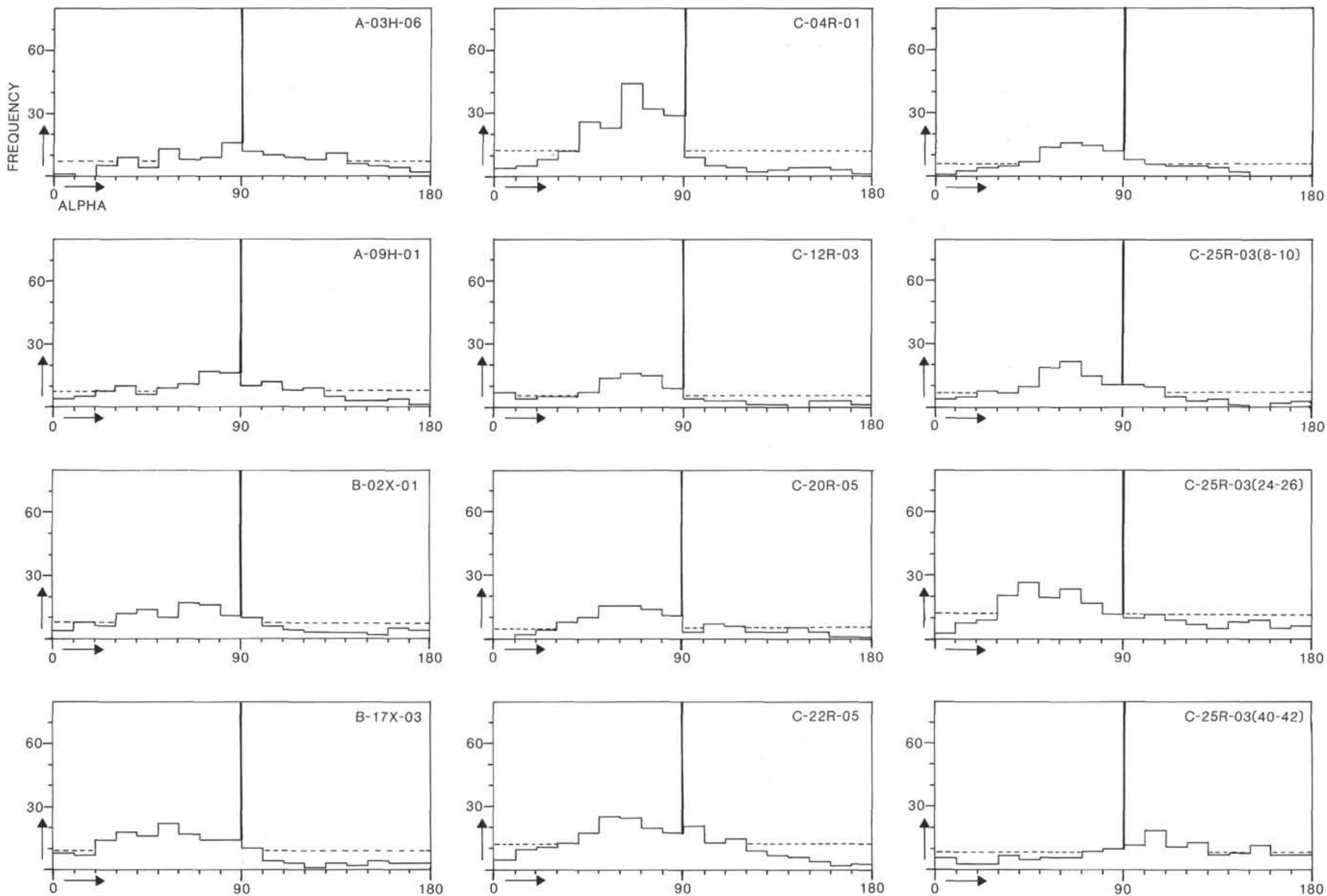

Figure 7. Frequency distributions of basal trace orientations of detrital illite with respect to the core axis. The core axis is represented by the bold vertikal lines in the diagrams. Dashed horizontal lines are mean frequencies. 
Table 2. Texture analyses.

\begin{tabular}{lcl}
\hline Sample No. 131-808- & & $\mathrm{I}_{\max } \mathrm{e}_{\mathrm{z}}$ \\
\hline $\mathrm{A}-3 \mathrm{H}-1,19-21 \mathrm{~cm}$ & (dried) & $1.6-$ \\
$\mathrm{A}-9 \mathrm{H}-1,139-141$ & (dried) & $1.6-$ \\
$\mathrm{B}-2 \mathrm{X}-1,15-17$ & (dried) & $1.6-0.21$ \\
$\mathrm{~B}-17 \mathrm{X}-3,70-72$ & (dried) & $1.7-0.23$ \\
$\mathrm{C}-4 \mathrm{R}-1,123-125$ & (dried) & $2.2-0.33$ \\
$\mathrm{C}-4 \mathrm{R}-1,123-125$ & (wet) & $2.2-0.33$ \\
$\mathrm{C}-12 \mathrm{R}-3,32-34$ & (dried) & $2.0-0.29$ \\
$\mathrm{C}-12 \mathrm{R}-3,32-34$ & (wet) & $1.7-0.23$ \\
$\mathrm{C}-20 \mathrm{R}-5,78-80$ & (dried) & $2.2-0.33$ \\
$\mathrm{C}-22 \mathrm{R}-5,46-48$ & (dried) & $1.7-0.23$ \\
C-25R-3, 8-10 & (dried) & $2.0-0.29$ \\
C-25R-3, 24-26 & (dried) & $1.9-0.27$ \\
C-25R-3, 24-26 & (wet) & $1.9-0.27$ \\
C-25R-3, 40-42 & (dried) & $2.5-0.37$ \\
\hline
\end{tabular}

Table 3. Results of FRY/PODI strain analyses.

\begin{tabular}{lccccc}
\hline Sample No. 131-808- & $R_{\mathrm{f}}$ FRY & PODI & $\mathrm{e}_{\mathrm{z}}$ FRY & PODI & Marker type \\
\hline A-9H-1, 139-141 cm & 1.48 & - & -0.32 & - & opaques \\
A-9H-1, 139-141 & - & 1.59 & - & -0.37 & illite \\
B-2X-1, 15-17 & - & 1.55 & - & -0.36 & illite \\
B-17X-3, 70-72 & 1.6 & 1.36 & -0.38 & -0.27 & opaques \\
C-20R-5, 78-80 & 1.61 & 1.56 & -0.38 & -0.36 & opaques \\
C-22R-5, 46-48 & - & 1.7 & - & -0.41 & opaques \\
C-25R-3, 24-26 & 1.59 & - & -0.37 & - & opaques \\
C-25R-3, 24-26 & - & 1.38 & - & -0.28 & illite \\
\hline
\end{tabular}

Table 4. March (1932) strain analyses.

\begin{tabular}{lrrc}
\hline Sample No. 131-808- & $\mathrm{f}_{\max }$ & $\mathrm{f}_{\text {uniform }}$ & $\mathrm{f}_{\max } / \mathrm{f}_{\text {uniform }} \mathrm{e}_{\mathrm{z}}$ \\
\hline A-3H-1, 19-21 & 16 & 7.3 & $2.2-0.32$ \\
$\mathrm{~A}-9 \mathrm{H}-1,139-141$ & 17 & 7.8 & $2.2-0.32$ \\
$\mathrm{~B}-2 \mathrm{X}-1,15-17$ & 17 & 7.6 & $2.3-0.33$ \\
B-17X-3, 70-72 & 22 & 9.1 & $2.4-0.36$ \\
C-4R-1, 123-125 & 44 & 12.2 & $3.6-0.47$ \\
C-12R-3, 32-34 & 16 & 5.6 & $2.9-0.41$ \\
C-20R-5, 78-80 & 16 & 6.2 & $2.6-0.38$ \\
C-22R-5, 46-48 & 26 & 12.6 & $2.1-0.31$ \\
C-25R-3, 8-10 & 22 & 7.6 & $2.9-0.41$ \\
C-25R-3, 24-26 & 27 & 11.8 & $2.3-0.34$ \\
C-25R-3, 40-42 & 19 & 8.4 & $2.3-0.34$ \\
\hline
\end{tabular}

from porosity data. Uniaxial shortening $\left(e_{z}\right)$ due to porosity loss can be computed from porosity data using the expression

$$
e_{z}=\left(P_{0}-P\right) / P-100 ;
$$

where $\mathrm{P}_{\mathrm{o}}$ is the initial porosity of the sediment before compaction, and $\mathrm{P}$ is the measured porosity (see also Oertel and Curtis, 1972). Taking a mean function (see Fig. 2) derived from the shipboard porosity data of Site 808 (Taira, Hill, Firth, et al., 1991), we arrive at the exponential graph shown in Figure 10. Initial porosity was taken to be $65 \%$. All strain data from smectite textures (solid squares) lie to the right of this graph. Strain data derived from illite orientations (solid lozenges) and measurements using the Fry and PODI techniques (open circles) straddle the graph below $250 \mathrm{mbsf}$, but strains are significantly higher in the upper $120 \mathrm{~m}$ of the sediment column. We might speculate that this high degree of preferred orientation is a remnant of an initial fabric acquired during the sedimentation process, especially as it does not show in the smectite textures, which are initially isotropic as a result of flocculated sedimentation (cf. van Olphen, 1963). On the other hand, we have to bear in mind that the Site 808 graph in Figure 10 is derived from a mean porosity curve and not from porosity measurements made on the samples studied. Thus, much of the mismatch may not be meaningful. Overall, however, the fit of the strain data from fabrics and from porosities seems to improve below $250 \mathrm{mbsf}$. We have also calculated $\mathrm{e}_{\mathrm{z}}$ from the porosity-depth functions of Hamilton (1976), Sclater and Christie (1980), and Athy (1930). None of three functions, however, fits the strain data from microfabrics better than the Site 808 curve (see Fig. 10).

\section{DISCUSSION OF RESULTS}

\section{Sedimentation Processes and Diagenetic Mechanisms}

What do our data reveal about the sedimentary environment and mechanisms of mudstone diagenesis? For illite fabrics (circles and lozenges in Fig. 10) the compactional strain values from the upper part of the borehole are significantly higher than those obtained by the porosity data, and indicate the presence of a primary preferred orientation of the detrital illite that must have been acquired during the sedimentation process. The exceptionally high degree of preferred orientation cannot be explained by an alternative mechanism. The strain data from smectite textures (solid squares in Fig. 10, Fig. 6, Table 3 ) for the upper 350 mbsf suggest two things.

1. The smectite was sedimented as flocculated aggregates with random particle orientations from an electrolyte-rich water column (see, e.g., Whitehouse et al., 1960; van Olphen, 1963) to generate the typical "honeycomb" microstructure mentioned by Terzaghi (1925) which is in fact evident in specimens A-3H-6 and A-9H-1 (Fig. 6). This is interpreted as reflecting a marine environment and oxidizing conditions in the bottom water column (see review of Moon and Hurst, 1984). Reducing conditions in a black shale environment would have had the effect of destroying the flocculated aggregates in the water column before sedimentation.

2. The preferred orientation was acquired by breakdown of microporosity in the smectite aggregates. Especially in specimens B-2X-1 and $\mathrm{C}-4 \mathrm{R}-1$, there is a very good fit of the strains derived from porosity reduction and from smectite textures. As mentioned above the low degree of smectite-preferred orientation below $400 \mathrm{mbsf}$ may reflect the onset of smectite recrystallization where micropores are closed by neoformation of minerals rather than by fabric collapse.

\section{Lateral Component of Shortening}

The three qualifiers for the detection of a lateral component of shortening mentioned in the introductory chapter will be used as a starting point of discussion.

\section{Triaxial Strains and Fabrics.}

The smectite textures represent truly three-dimensional analyses, and in most cases axial symmetry of the preferred orientation patterns is evident (Fig. 6). Exceptions are specimens A-3H-6 and A-9H-1, in which the preferred orientation patterns relate to incomplete destruction of honeycomb texture due to low deformation, and cannot be used to qualify lateral shortening. Slight departures from axial symmetry in specimens C-4R-1 (wet) and C-12R-1 (wet) might indicate triaxial strain geometry and therefore a small component of lateral shortening to the total strain.

\section{Nonvertical Orientations of $Z$.}

Smectite pole figure maxima (Fig. 6) are consistently inclined with respect to the vertical. With the exception of specimens A-3H-6 and A-9H-1, the same is true for all frequency distributions of poles to illite traces in two-dimensional section parallel to the core axis (Fig. 7). The inclinations of the maxima relative to the vertical are typically $30^{\circ}$ to $40^{\circ}$, broadly in line with the evidence from the smectite textures. The absence of inclined maxima in specimens A-3H-6 and A-9H-1 indicates that Z (Fig. 1) is vertical, as would be 

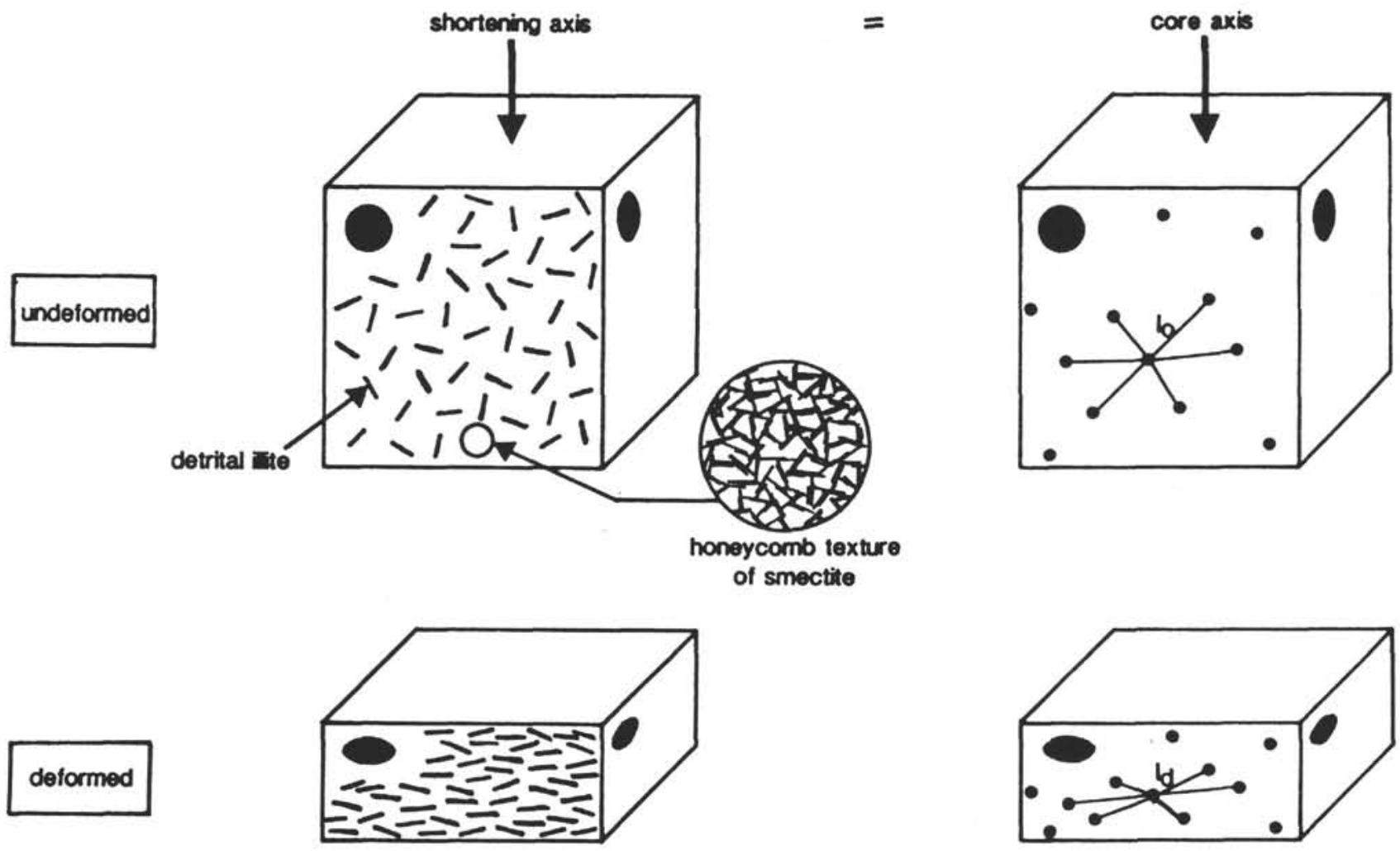

$I_{0} \neq I_{d}$ : this describes stretch: $s=\frac{I_{0}}{I_{d}}$

March-type strain analysis

on deformed

smectite aggregates:

$\theta_{z}=I_{\max }-1 / 2.1$

on rotated

detrital illites:

$e_{z}=\left[1 /\left(f_{\max } / f_{\text {uniform }}\right)\right]^{1 / 2}-1$
Fry/Podi type strain analysis

on distorted

point distributions:

$e_{z}=\left(1 / R_{f}\right)-1$

$\theta_{\mathbf{Z}}=$ minimum principal elongation

$R_{f}=$ axial ratio of finite strain ellipse

$I_{\max }=$ maximum intensity of diffracted $x$-ray beam parallel to core axis

$f_{\max }=$ maximum occurrence of illite (001) traces

$f_{\text {uniform }}=$ uniform occurrence of illite (001) traces

Figure 8. Fabrics and strain: sketches showing the basis for strain calculations using March (1932) type analysis of crystallographic preferred orientations (left) and Fry/PODI type analysis on distorted orientation distributions of initially homogeneous marker particle populations. 
A

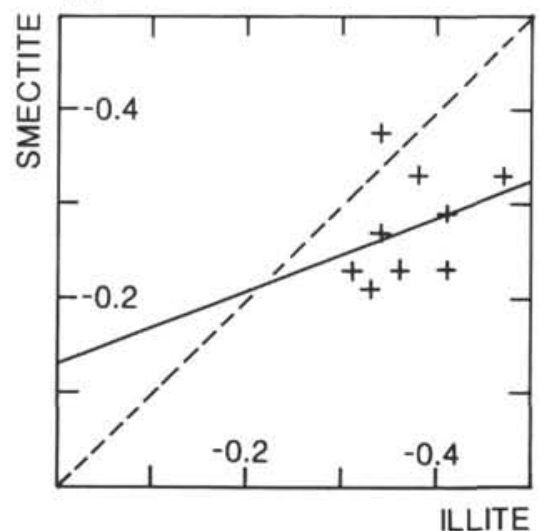

B

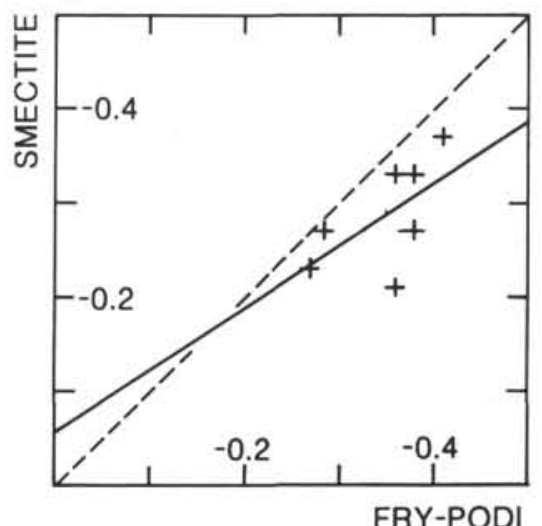

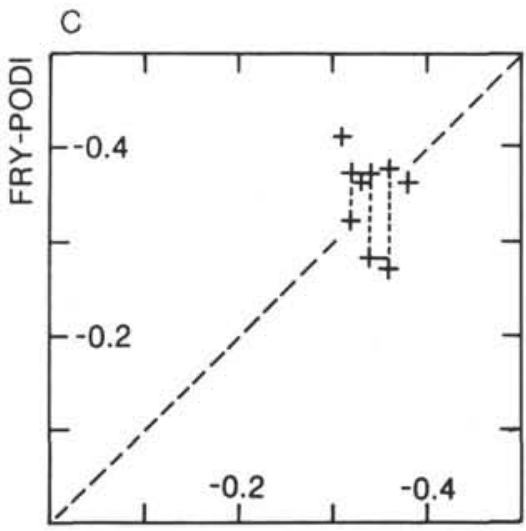

ILLITE

Figure 9. Diagrams relating strain data from smectite textures, illite-preferred orientations, and Fry-PODI analyses of marker particle fabrics. Dashed lines are the symmetry axis of the diagrams, solid lines are graphs obtained by linear regression of the data. Correlation coefficients are 0.35 in left diagram and 0.6 in center diagram. See text.

theoretically expected at shallow borehole depths. The data in Figures 6 and 7 clearly speak in favor of a component of lateral shortening in total deformation.

\section{Low Strain Ellipticities $\left(R_{\mathrm{f}}\right)$.}

An indirect comparison of strain data from porosity and microfabrics (Fig. 10) does not allow us to identify a component of lateral shortening. As seen from the discussion above, too many variables influence the initial orientation distribution of the illite and other marker particles. From the data it seems that microfabrics do react to compression, but the initial state is not very well defined. Therefore interpretations based on the evaluation of strain magnitudes should be avoided, and we note that mud microfabrics are not very precise indicators of strain.

In summary, however, from criteria (1) and (2) we cautiously propose that there is a component of lateral shortening visible in the mudrocks of Site 808 , but it is probably small if compared with the magnitude of uniaxial vertical shortening due to load-induced progressive dewatering and reduction in pore space. It is not obvious whether the lateral shortening is produced by toe contraction of the accretionary wedge or by deformation due to gravitational sliding of large rock units. The paucity of slump-related rocks and structures at Site 808, especially below 20 mbsf (Taira, Hill, Firth, et al., 1991) suggests, however, that toe contraction may be the more likely cause.

\section{SUMMARY AND CONCLUSION}

The results of quantitative microfabric studies on mudstone samples from the top 550 mbsf of Site 808 can be used to make inferences about:

1. Strain geometry. Axially symmetric (001) pole maxima of smectite indicate a strain path of progressive flattening, closely related to loss of pore space by vertical loading.

2 . The relative importance of lateral vs. vertical shortening in the off-scraped sediment sequence. A component of bulk lateral shortening is detectable in the top $550 \mathrm{mbsf}$ at Site 808 , but its relative magnitude is probably small.

3. Diagenetic mechanisms. Micropore collapse is an important fabric building process. Below 400 mbsf smectite recrystallization possibly randomizes crystallographic preferred orientation patterns.

4. The sedimentary environment. Flocculated sedimentation of smectite suggests marine conditions and an oxic bottom water column.
5. The suitability of quantitative fabric studies for strain analysis. Mud microfabrics are not very precise strain gauges due to uncertainties about initial orientations and spatial distributions of the marker minerals used. They can, however, be successfully used for rough strain estimations.

\section{ACKNOWLEDGMENTS}

This paper was reviewed by Rob Knipe and Yujiro Ogawa. We are grateful for their suggestions and comments. We thank ODP Leg 131 shipboard scientists Warner Brückmann, Dan Karig, and Alex Maltman for discussions and for background information not available to shore-based contributors like us. Wolfgang Unzog is acknowledged for providing perfect computer software support. Susanne Schweigel helped us to catch a glimpse of the miracles of statistics. This study was financially supported by Deutsche Forschungsgemeinschaft (grants Bel041/5-1 and 5-2 to JHB).

\section{REFERENCES}

Agar, S.M., Prior, D.J. and Behrmann, J.H., 1989. Back-scattered electron imagery of the tectonic fabrics of some fine-grained sediments: implications for fabric nomenclature and deformation processes. Geology, 17:901-904.

Aoki, Y., Tamano, T., and Kato, S., 1982. Detailed structure of the Nankai Trough from migrated seismic sections. In Watkins, J., and Drake, C.L. (Eds.), Studies in Continental Margin Geology. AAPG Mem., 34:309-322.

Athy, L.F., 1930. Density, porosity, and compaction of sedimentary rocks. AAPG Bull., 14:24.

Behrmann, J.H., 1991. Texturentwicklung in feinkörnigen, marinen Tongesteinen. Probenbearbeitung ODP Legs 128 und 131 (Japan-See, Nankai). Working Rep., DFG Project Be1041/5-1 "Tontexturen."

Boyce, R.E., 1976. Definitions and laboratory techniques of compressional sound velocity parameters and wet-water content, wet-bulk density, and porosity parameters by gravimetric and gamma ray attenuation techniques. In Schlanger, S.O., Jackson, E.D., et al., Init. Repts. DSDP, 33: Washington (U.S. Govt. Printing Office), 931-958.

Brückmann, W., 1989. Typische Kompaktion mariner Sedimente und ihre Modifikation in einem rezenten Akkretionskeil (Barbados Ridge). Tub. Geowiss. Abh., A5:1-135.

Davis, D., Suppe, J., and Dahlen, F.A., 1983. Mechanics of fold-and-thrust belts and accretionary wedges. J. Geophys. Res., 88:1153-1172.

Fry, N., 1979. Random point distributions and strain measurement in rocks. Tectonophysics, 60:89-105.

Hamilton, E.L., 1976. Variations of density and porosity with depth in deep sea sediments. J. Sediment. Petrol., 46:280-300. 
Knipe, R., 1986. Deformation mechanism path diagrams for sediments undergoing lithification. In Moore, J.C. (Ed.), Structural Fabrics in Deep Sea Drilling Project Cores from Forearcs. Mem.-Geol Soc. Am., 166:151-160.

Lipshie, S.R., 1984. Development of phyllosilicate preferred orientation in naturally and experimentally metamorphosed and deformed rocks [Ph.D. thesis]. Univ. California, Los Angeles.

March, A., 1932. Mathematische Theorie der Regelung nach der Korngestalt bei affiner Deformation. Z. Kristallogr., 81:285-297.

Moon, C.F., and Hurst, C.W., 1984. Fabrics of muds and shales: an overview. Geol. Soc. Spec. Publ. London, 15:579-593.

Oertel, G., 1985. Reorientation due to grain shape. In Wenk, H.-R. (Ed.), 1985. Preferred Orientation in Deformed Metals and Rocks: an Introduction to Modern Texture Analysis: Orlando (Academic Press), 259-265.

Oertel, G., and Curtis, C.D., 1972. Clay-ironstone concretion preserving fabrics due to progressive compaction. Geol. Soc. Am. Bull., 83:2597-2606.

Prior, D.J., and Behrmann, J.H., 1990a. Backscatter SEM imagery of finegrained sediments from Site 671, Leg 110-preliminary results. In Moore, J.C., Mascle, A., et al., Proc. ODP, Sci. Res., 110: College Station, TX (Ocean Drilling Program), 245-255.

, 1990b. Thrust related mudstone fabrics from the Barbados forearc: a backscattered SEM study. J. Geophys. Res., 95:9055-9067.

Ramsay, J.G., and Huber, M.I., 1983. The Techniques of Modern Structural Geology (Vol. 1): Strain Analysis: London (Academic Press).

Schiller, H.-J., 1980. Röntgenographische Texturuntersuchungen an feinkörnigen Sedimenten unterschiedlicher Kompaktion. Bochumer Geol. Geotechn. Arb., 4:1-108.

Sclater, J.G., and Christie, P.A.F., 1980. Continental stretching: an explanation of the post-mid-Cretaceous subsidence of the Central North Sea basin. $J$. Geophys. Res., 85:3711-3739.

Siddans, A.W.B., 1976. Deformed rocks and their textures. Trans. R. Soc. London A, 283:43-54.
Taira, A., Hill, I., Firth, J.V., et al., 1991. Proc. ODP, Init. Repts., 131: College Station, TX (Ocean Drilling Program).

Terzaghi, K., 1925. Erdbaumechanik auf bodenphysikalischer Grundlage: Leipzig (Deuticke).

Unzog, W., 1990. Beispiele von Strainanalysen in Kristallingebieten. In TSK III, 3. Symp. für Tektonik, Strukturgeol. und Kristallingeol. Kurzfassungen der Vorträge und Poster. Graz, 265-266.

van Olphen, H., 1963. An Introduction to Clay Colloid Chemistry: New York (Wiley).

von Engelhardt, W., and Gaida, K.H., 1963. Concentration changes of pore solutions during the compaction of clay sediments. J. Sediment. Petrol., 33:919-930.

von Gehlen, K., 1960. Die röntgenographische und optische Gefügeanalyse von Erzen, insbesondere mit dem Zählrohr-Texturgoniometer. Beitr. Mineral. Petrol., 7:340-388.

Weber, K., 1976. Gefügeuntersuchungen an transversalgeschieferten Gesteinen, aus dem östlichen Rheinischen Schiefergebirge (Ein Beitrag zur Genese der transversalen Schieferung). Geol. Jahrb., D15:3-98.

Wenk, H.R., 1985. Preferred Orientation in Deformed Metals and Rocks: an Introduction to Modern Texture Analysis: Orlando (Academic Press).

Whitehouse, U.G., Jeffrey, L.M., and Debbrecht, J.D., 1960. Differential settling tendencies of clay minerals in saline waters. Clays Clay Miner., Proc. Nat. Conf. Clays Clay Miner., 7:1-79.

Wood, D.S., and Oertel, G., 1980. Deformation in the Cambrian slate belt of Wales. J. Geol., 88:309-326.

Date of initial receipt: 14 October 1991

Date of acceptance: 11 September 1992

Ms 131SR-106 


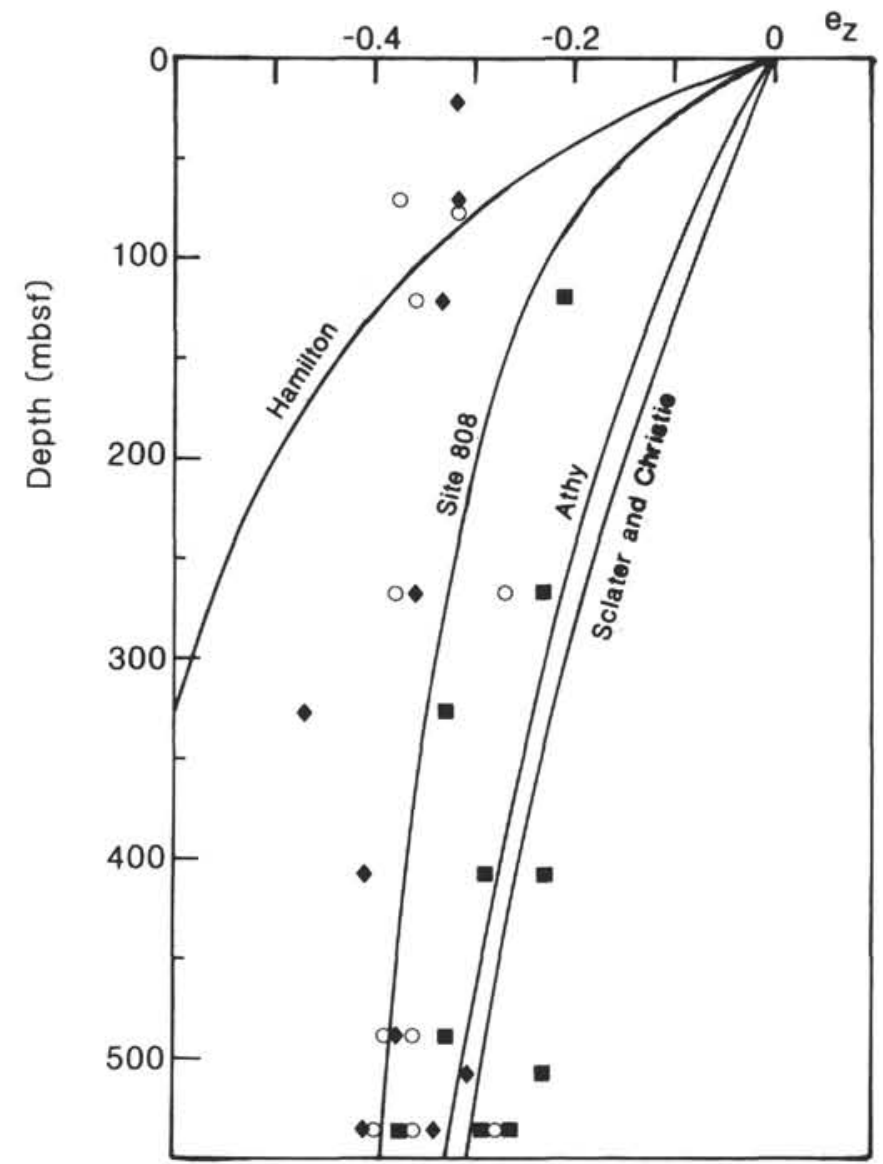

Figure 10. Strain vs. depth in the upper $550 \mathrm{mbsf}$ of Site 808. Graphs present strain-depth functions computed from the porosity data of Site 808 , and the porosity-depth relationships of Hamilton (1976), Sclater and Christie (1980), and Athy (1930). Solid squares are strains from smectite textures, solid lozenges are strains from illite-preferred orientations, and open circles are strains from Fry/PODI analyses. See text. 